\title{
The HIV-1 Tat protein activates transcription from an upstream DNA-binding site: implications for Tat function
}

\author{
Christopher D. Southgate and Michael R. Green \\ Program in Molecular Medicine, University of Massachusetts Medical Center, Worcester, Massachusetts 01605 USA
}

\begin{abstract}
The Tat protein of human immunodeficiency virus type 1 (HIV-1) activates transcription following binding to nascent trans-activation response (TAR) RNA downstream of the transcription start site. Because Tat functions when bound to RNA, and in a position-dependent manner, it has been proposed that Tat works by a novel mechanism. Here, we perform a series of protein fusion experiments that reveal striking similarities between Tat and conventional cellular activators. Most significantly, we demonstrate that Tat can function when bound to upstream promoter DNA. This activity depends on a region within Tat that is also required for Tat to function when bound to TAR RNA. In contrast, the arginine-rich region of Tat, which is required for binding to TAR RNA, is dispensable for the function of DNA-bound Tat. When bound either to RNA or DNA Tat activity requires cooperation with promoter-bound cellular transcription factors. Finally, we show that Tat and a strong acidic activator stimulate transcription to comparable levels. On the basis of these and other results we suggest that Tat and acidic activators act on a similar step in the transcription process.
\end{abstract}

[Key Words: Tat protein; HIV-1; transcriptional activation; TAR RNA]

Received September 11, 1991; revised version accepted October 9, 1991.

A typical eukaryotic transcriptional activator comprises two separable functional domains: a transcriptional activating region and a promoter-binding domain (for review, see Ptashne 1988). The promoter-binding domain confers specificity by targeting an activating region to a given promoter either through a sequence-specific nucleic acid-binding activity or a protein-protein interaction with a DNA-bound protein. Protein fusion experiments have shown that these two domains are modular: Each is a separable functional unit that can be joined to the complementary region of an unrelated activator to create a functional hybrid activator (Ptashne 1988). On the basis of their amino acid composition, activating regions have been grouped into different classes (for review, see Mitchell and Tiian 1989): those rich in acidic residues (acidic activators; for review, see Ptashne 1988), glutamines (glutamine-rich activators; Courey and Tijan 1988), and prolines (proline-rich activators; Mermod et al. 1989|, as well as those containing amino acids of all classes, such as the adenovirus Ela-activating region (Lillie and Green 1989; Martin et al. 1990). The promoter-bound activating region is believed to function by interacting, directly or indirectly, with one or more basic transcription factors (for review, see Lewin 1990; Ptashne and Gann 1990; Sharp 1991).

The Tat protein of the human immunodeficiency virus type 1 (HIV-1) is an extremely potent activator of
HIV-1 long terminal repeat (LTR) transcription (for review, see Rosen and Pavlakis 1990; Cullen 1990; Vaishnav and Wong-Staal 1991). Several aspects of the mechanisms of action of Tat appear to differ significantly from those usually attributed to typical transcriptional activators. In particular, the specificity of Tat action is dictated by a trans-activation response (TAR) site located $\sim 40$ bp downstream of the transcriptional initiation site (for review, see Sharp and Marciniak 1989). Tat activation requires sequences between +19 and +42 relative to the cap site $(+1)$ that coincide with a phylogenetically conserved RNA stem-and-loop secondary structure (Muesing et al. 1987; Hauber and Cullen 1988; Jakobovits et al. 1988; Selby et al. 1989). In vitro-binding studies show that Escherichia coli-derived recombinant Tat protein or Tat peptides can bind specifically to TAR RNA (Dingwall et al. 1989,1990; Cordingley et al. 1990: Roy et al. 1990a; Weeks et al. 1990; Calnan et al. 1991 a, b; Weeks and Crothers 1991).

Direct evidence for transcriptional activation from nascent RNA was provided by fusing Tat to the unrelated RNA-binding proteins HIV-1 Rev (Southgate et al. 1990) or R17 (Selby and Peterlin 1990). The resulting chimeric proteins activated transcription from a reporter in which the TAR element had been replaced by the appropriate RNA-binding site. It has also been reported that a TatJun chimeric protein could activate transcription when 
bound to AP-1 DNA-binding sites inserted downstream of the transcriptional initiation site (Berkhout et al. 1990). We note, however, that function through the AP1-binding sites was diminished significantly compared with function through TAR. Moreover, this Tat-Jun chimeric protein activated transcription only when two AP-1 sites were positioned in an inverted orientation, and the Tat-Jun protein did not function when the AP-1 sites were inserted upstream of the transcription start site (Berkout et al. 1990). The orientation dependence and position dependence of the AP-1 sites in these experiments raise the possibility that the Tat-Jun protein activated transcription by binding to nascent RNA rather than DNA.

Tat therefore appears to differ fundamentally from typical transcriptional activators because it can only function downstream of the transcription start site and perhaps only through nascent RNA. These observations in conjunction with other, more direct evidence /Marciniak et al. 1990b; Feinberg et al. 1991) have led to the proposal that Tat functions at transcriptional elongation by, for example, increasing the processivity of RNA polymerase II (Cullen 1990). The cited precedent is that of bacteriophage antiterminators, which also function through RNA-binding sites (Lazinski et al. 1989).

Here, we perform a series of protein fusion experiments, which demonstrate for the first time that Tat can function when bound to DNA upstream of the transcription start site. These and other experiments reveal common properties between Tat and typical transcription activators.

\section{Results}

Activation by Tat requires cooperation with cellular transcription factors

We initially tested the ability of Tat to function with various cellular transcription factors. Previous studies have addressed this issue by inserting the TAR element into different promoters and testing the ability of these hybrid promoters to support a Tat response (Rosen et al. 1985; Peterlin et al. 1986). These results have been variable most likely because of differences in the promoters tested and the context of the inserted TAR element. To circumvent these difficulties we constructed deletions of the HIV-1 LTR and then added back transcription factorbinding sites. Thus, we analyzed, in the same promoter context, the ability of different cellular transcription factors to cooperate with Tat.

Figure 1A defines by deletion analysis the transcription factor DNA-binding sites required for Tat activation. HIV-1 LTR deletions that sequentially remove the NF- $k B$ or Spl DNA-binding sites were linked downstream of the TAR element to the bacterial chloramphenicol acetyltransferase (CAT) gene and cotransfected into either HeLa or Jurkat cells in the presence or absence of a cytomegalovirus immediate early (CMV-IE) promoter-driven Tat expression plasmid (CMV-cTat;
Cullen 1986). CAT activity was taken as a measure of transcription activation. Previous studies analyzing Tat function in mammalian cell cotransfection experiments have established that CAT activity is a valid measure of steady-state CAT mRNA levels (Peterlin et al. 1986; Muesing et al. 1987; Jakobovits et al. 1988; Rice and Mathews 1988). The results in Figure 1A indicate that no significant effect on Tat activation was observed in HeLa cells or Jurkat cells (data not shown) when sequences upstream of position -83 were removed (Fig. 1A, lanes 1-6). However, activation was severely impaired by deleting sequences between -83 and -69 (lanes 7,8 ) corresponding to the distal high-affinity Spl site III (Jones et al. 1986). Deletion to position -31, immediately upstream of the TATA box, abolished activation (lanes $9,10)$. We conclude from these results that sequences between -83 and -69 are essential for efficient activation by Tat, consistent with several previous reports (Harrich et al. 1989; Leonard et al. 1989; Berkhout et al. 1990; Zimmermann et al. 1991)

Sequences between positions -77 and -45 comprise three Spl-binding sites (Jones et al. 1986). To define the potential role and specificity of Sp-1 in the Tat response, oligonucleotides containing consensus DNA-binding sites for three different cellular transcription factors (Spl, ATF, or USF) were cloned in tandem immediately upstream of the TATA box in the -31 deletion mutant and assayed for Tat activation. The results of Figure 1B show that all three promoters supported Tat activation in HeLa cells, and similar results were obtained in Jurkat cells (data not shown). There are several reasons why Tat activation of these different reporters cannot be directly compared with one another: The number of transcription factor-binding sites inserted differs (five $\mathrm{Spl}$ sites vs. only two ATF or USF sites), the optimal spacing between TAR and these sites is not known and, finally, transcription in the absence of Tat cannot be measured accurately. On the basis of these observations we draw two conclusions: First, an efficient Tat response requires the presence of cellular transcription factor-binding sites upstream of the TATA box and, second, several unrelated cellular transcription factors can support a Tat response.

\section{GAL4 derivatives can support Tat activation}

To confirm and extend the conclusions of Figure 1B, we tested the ability of three defined transcriptional activating domains to support a Tat response: the glutaminerich activating region of Spl (Courey and Tiian 1988), the acidic activating region of VP16 (Sadowski et al. 1988; Triezenberg et al. 1988), and the zinc-containing activating region of the adenovirus Ela protein (Lillie and Green 1989|. Each of these activating regions was fused inframe to the DNA-binding domain of the GAL4 protein, GAL4(1-147). The reporter contained either one or five GAL4 DNA-binding sites inserted immediately upstream of the HIV-1 LTR TATA box [G1 and G5 $(-31)$ HIV LTR; Fig. 2A]. Each GAL4 derivative was then 
A

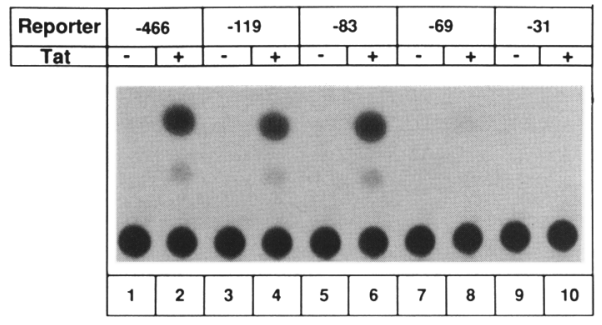
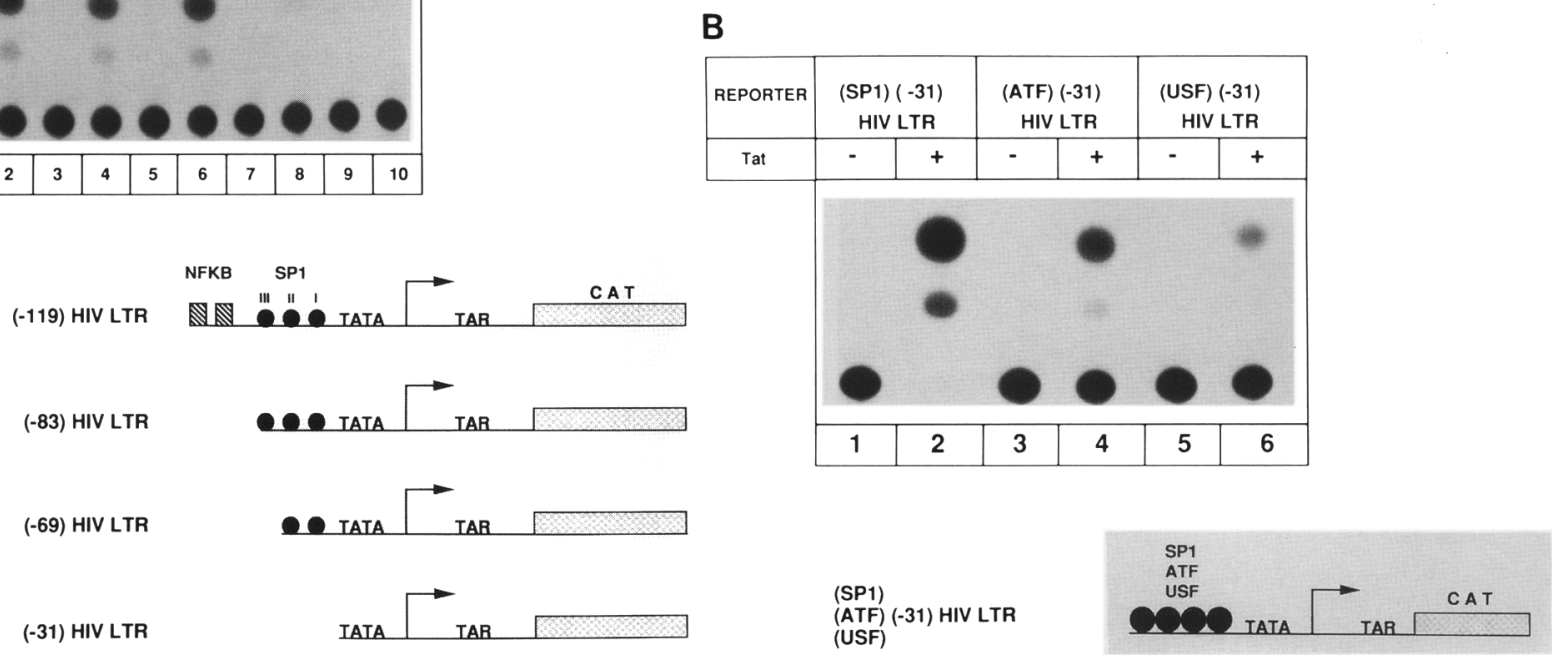

Figure 1. Tat function requires cooperation with cellular transcription factors. $(A)$ Sequences downstream of position -83 are essential for Tat activation of the HIV-1 LTR. The HIV-1 LTR is shown schematically containing two NF- $\mathrm{BB}$-binding sites positioned between -105 and -80 , three Spl sites between positions -77 and -45 (sites III-I), a TATA box and the TAR element. Sequential deletions that remove either the NF- $\mathrm{KB}$ or Spl sites were introduced into the HIV-1 LTR and linked downstream of the TAR element $(a t+84)$ to the bacterial CAT gene. Each HIV-1 LTR deletion mutant reporter was then cotransfected, together with CMV-cTat or CMV vector and CH1 10 reference plasmid, into HeLa cells by calcium phosphate coprecipitation. Cells were harvested after $48-72$ hr and assayed for CAT activity. The unacetylated and acetylated forms of $\left[{ }^{14} \mathrm{C}\right]$ chloramphenicol were then separated by thin-layer chromatography and detected by autoradiography. $(B)$ Addition of consensus DNA-binding sites for Sp1, ATF, or USF immediately upstream of the HIV-1 LTR TATA box restores Tat function. Oligonucleotides comprising DNA-binding sites for the transcription factors Spl, ATF, and USF were cloned immediately upstream of the HIV-1 LTR TATA box in the (-31) HIV LTR reporter as depicted schematically below the autoradiograph. Each add-back reporter was then cotransfected in the absence or presence of CMV-cTat expression plasmid and $\mathrm{CH} 110$ reference plasmid into HeLa cells by calcium phosphate coprecipitation. Cells were harvested after 48-72 hr, and steady-state CAT activity was determined.

cotransfected with either one of these reporter plasmids into HeLa cells in the absence or presence of the Tat expression plasmid.

The results of Figure 2A show that all three activating regions were able to support a Tat response (lanes 5-16). In contrast, GAL4(1-147), which lacks a transcriptional activating domain, did not support Tat activation (lanes 1-4). The results also show that as the level of transcription in the absence of Tat increases, the effect of Tat decreases. For example, Tat has the largest effect with GAL4-Spl, which on its own elicits a very low level of transcription with either one or five GAL4-binding sites. With Gal4-Ela and Gal4-VP16, as the number of GAL4binding sites increases from one to five, the level of transcription rises and the fold induction by Tat decreases. For example, with five GAL4-binding sites Tat has less than a twofold effect with GAL4-VP16 and less than a threefold effect with GAL4-Ela. In summary, the combined results with all three activators clearly show that Tat responsiveness is inversely proportional to the level of transcription observed in the absence of Tat.

It was possible that the lack of a significant Tat response when transcription is already at a high level was the result of some other limitation, such as the transla- tional capacity of the transfected cell. To exclude this possibility, decreasing amounts of the G5 $(-31)$ HIV LTR reporter ( $1 \mu g-40 \mathrm{ng}$ ) were cotransfected with a constant amount of GAL4-VPl6 $(1 \mu \mathrm{g})$ in the presence or absence of the Tat expression plasmid $(1 \mu \mathrm{g})$ (Fig. 2B). In all instances, Tat activation was less than threefold, although the absolute level of CAT activity decreased significantly. Thus, the diminished Tat activation when five GAL4-VP16 molecules are bound to the upstream promoter is not the result of some limitation of the transfected cell.

On the basis of these results, we draw the following conclusions. First, Tat responsiveness requires a promoter-bound transcriptional activating region. Second, three unrelated transcriptional activation domains can support Tat responsiveness to various levels. Third, optimal Tat activation is obtained with the glutamine-rich activation region of $\mathrm{Spl}$, which on its own elicits a very low level of transcription. Fourth, the fold induction by Tat is inversely proportional to the level of transcription observed in the absence of Tat. Finally, the maximal level of transcription observed with Tat is comparable to that elicited by the potent acidic activator GAL4-VP16 (Fig. 2A, cf. lanes 8 and 11). 
A

\begin{tabular}{|c|c|c|c|c|c|c|c|c|c|c|c|c|c|c|c|c|}
\hline GAL4 Derivative & \multicolumn{4}{|c|}{ GAL4 (1-147) } & \multicolumn{4}{|c|}{ GAL4-SP1 } & \multicolumn{4}{|c|}{ GAL4-VP16 } & \multicolumn{4}{|c|}{ GAL4-E1a } \\
\hline GAL4 Binding sties & & & & & & & & & & & 5 & 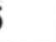 & & 1 & & \\
\hline Tat & - & + & - & + & - & + & - & + & - & + & - & + & - & + & - & + \\
\hline & 1 & 2 & 3 & 4 & 5 & 6 & 7 & 8 & 9 & 10 & 11 & 12 & 13 & 14 & 15 & 16 \\
\hline ACTIVATION & 1 & 1 & 1 & 1 & 1.7 & 55 & 2.7 & 241 & 4 & 36 & 151 & 255 & 4 & 28 & 66 & 140 \\
\hline
\end{tabular}

REPORTER :

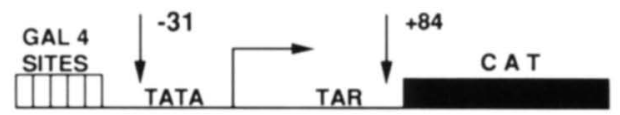

GAL4

DERIVATIVES : GAL4 (1-147) GAL4(1-147)

GAL4 - SP1

\begin{tabular}{|l|l|} 
GAL4 (1-147) & SP1 (region A) \\
\hline
\end{tabular}

GAL4 - VP16

GAL4 (1-147) $\quad$ VP16 $(413-490)$

GAL4 - E1a

GAL4 (1-147) $\quad$ E1a (121-223)

B

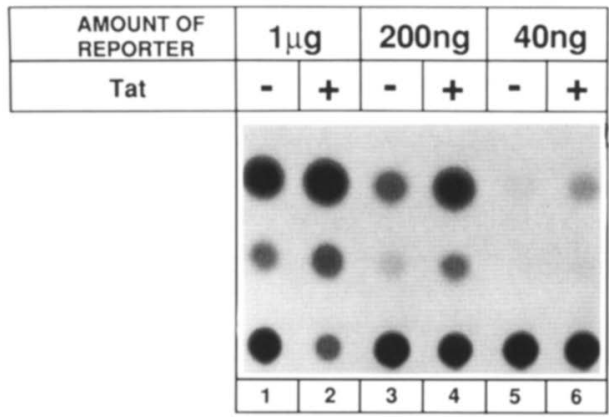

REPORTER :

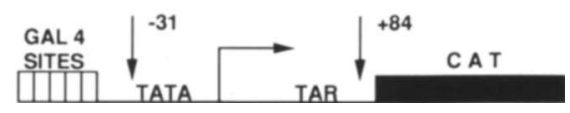

Figure 2. GAL4 derivatives can support Tat activation. $(A)$ Tat can cooperate with several unrelated transcriptional activation regions. One or five GAL4 17-mer DNA-binding sites were cloned immediately upstream of the TATA box in the $(-31)$ HIV LTR reporter [called G1 or G5 (-31) HIV LTR]. Activation region A of human Spl cDNA (Courey and Tjian 1988) was fused in-frame to the DNA-binding domain of GAL4 [GAL4 (1-147)|, and cloned into a mammalian expression vector (Sadowski and Ptashne 1989|. The GAL4-VP16 and GAL4-E1a expression plasmids have been described elsewhere (Sadowski et al. 1988; Lillie and Green 1989). The G1 or G5 (-31) HIV LTR reporters $(1 \mu \mathrm{g})$ were then transfected into HeLa cells using the DEAE-dextran technique together with a GAL4 derivative expression plasmid $(1 \mu \mathrm{g})$ in the presence or absence of CMV-cTat $(1 \mu \mathrm{g})$. After $48-72 \mathrm{hr}$, transient expression of steady-state CAT protein was measured. The nature of the GAL4 derivative cotransfected, the number of GAL4 sites within the reporter, and the relative CAT activity measured are indicated. $(B)$ Translation of CAT mRNA is not limiting. Decreasing amounts 11 $\mu \mathrm{g}-40 \mathrm{ng}$ ) of the G5 (-31) HIV LTR were transfected into HeLa cells by the DEAE-dextran technique, together with a constant amount of the GAL4-VP16 expression plasmid $(1 \mu \mathrm{g})$, in the presence or absence of CMV-Tat $(1 \mu \mathrm{g})$. CAT activity was assayed after 48-72 hr.

A GAL4-Tat fusion protein activates transcription when bound to DNA upstream of the transcription start site

The most unique aspect of Tat activation is the absolute requirement for the TAR RNA element. Recent protein fusion experiments (Berkhout et al. 1990; Selby and Peterlin 1990; Southgate et al. 1990) suggest that the sole function of TAR is to recruit Tat into the vicinity of the promoter. A prediction of this idea is that Tat will activate transcription when bound to DNA upstream of the transcription start site.

To test this prediction the Tat cDNA was fused inframe to the GAL4 DNA-binding domain, GAL4(1-147). This GAL4-Tat protein has complete Tat activity: GAL4-Tat and Tat-activated transcription from the HIV 
LTR to comparable levels (Fig. 3A, lanes 2,3). The TAR element of each HIV LTR deletion mutant described in Figure 1A was removed, and six GAL4 DNA-binding sites were inserted immediately upstream of the deletion end point. These G6 HIV LTR $\triangle$ TAR deletion reporters were then cotransfected into HeLa cells together with either the Tat or GAL4-Tat expression plasmids.

Figure 3,A and B, shows, as expected, that Tat activated transcription from the wild-type HIV-1 LTR construct (Fig. 3A, lane 2) but not from any of the G6 HIV LTR $\triangle T A R$ promoters, which lack TAR (Fig. 3B, lanes $2,5,8,11,14,17)$. In contrast, GAL4-Tat activated transcription from the HIV-1 LTR promoter when tethered to RNA through the TAR element (Fig. 3A, lane 3) or when tethered to DNA through GAL4-binding sites (Fig. 3B, lane 3).

The results with the HIV LTR deletion mutants are remarkably similar to those in Figure 1A. Deletion to -83 had no significant effect on activation by GAL4 Tat (Fig. 3B, lane 6). In contrast, deletion of Spl site III significantly diminished activation by GAL4-Tat (lane 9), and deletion of all three Spl sites abolished activation by GAL4-Tat (lane 12). Also, as observed with TAR RNA-bound Tat (Fig. 2B), addition of Spl-binding sites to the -31 deletion mutant restored activation by GAL4 Tat to the full level (lane 15). Likewise, addition of USFbinding sites also allowed GAL4-Tat to activate transcription (lane 18).

Although the results of Figure 3B show that efficient activation by GAL4-Tat required promoter-bound transcription factors, we asked whether GAL4-Tat had any intrinsic activating potential. The results of Figure 3C show that six GAL4-Tat molecules bound immediately upstream of the TATA box elicted a low level of transcription. This activation is the result of Tat sequences: GAL4(1-147) alone (Fig. 3C, lane 2) failed to enhance transcription. We conclude that Tat in the absence of Spl has a weak transcriptional activating domain.

Figure 3D compares transcriptional activation by GAL4-Tat with that of the potent transcriptional acti- vator GAL4-VP16. The results show that on the G6 (-83) HIV LTR $\triangle$ TAR promoter, which contains three Spl sites, GAL4-Tat and GAL4-VP16 activated transcription to comparable levels. Hence, in the presence of Spl Tat is as potent an activator as GAL4-VP16.

\section{Mutational analysis of GAL4-Tat function}

We then determined the region of Tat required for activation when bound to DNA. Previous mutagenesis studies have defined four contiguous domains within the first 58 amino acids of HIV-1 Tat that are essential for function: an amino-terminal acidic domain (amino acids 1-21), a cysteine-rich region (amino acids 22-37), a highly conserved region (amino acids $41-47$ ), and an arginine-rich region required for RNA binding (amino acids 49-57) (see Fig. 4A, Garcia et al. 1988; Kuppuswamy et al. 1989; Rappaport et al 1989; Ruben et al. 1989; Rice and Carlotti 1990; Tiley et al. 1990).

We constructed previously described Tat amino acid substitution and deletion mutants into GAL4-Tat (Fig. $4 \mathrm{~A}$ ). These mutants were then cotransfected with either the HIV LTR or G6 $(-83)$ HIV LTR $\triangle T$ TAR promoters. Because GAL4-Tat can activate from either TAR (RNA) or GAL4 sites (DNA), the effect of mutations can be assessed in the same background. Previous studies have shown that each of these Tat mutants is expressed at levels comparable to wild type in transfected cells (Rice and Carlotti 1990|. Furthermore, the fact that the aminoterminal 147 amino acids of these derivatives are identical further ensures comparable protein levels.

The results of Figure 4B show that removal of the amino-terminal 21 residues of Tat abolished the ability of GAL4-Tat to activate transcription from both the HIV LTR and G6 $(-83)$ HIV LTR $\triangle T A R$ reporters (lane 3). Mutation of Cys-22 (lane 4) or His-33 (lane 5) within the cysteine-rich region and Phe-38 (lane 6) or Lys-41 (lane 7) within the conserved region also abolished the ability of GAL4-Tat to activate transcription from both the HIV LTR or G6 $(-83)$ HIV LTR $\triangle T A R$ reporters. In contrast,

\footnotetext{
Figure 3. A GAL4-Tat fusion protein can activate transcription from upstream DNA-binding sites. (A) A GAL4-Tat fusion protein activates transcription from the HIV LTR when tethered to TAR RNA. The $(-466)$ HIV LTR reporter, together with either Tat or GAL4-Tat expression plasmids, was cotransfected into HeLa cells by the calcium phosphate coprecipitation technique. Cells were harvested after $48 \mathrm{hr}$, and CAT activity was determined. (B) A GAL4-Tat fusion protein activates transcription from HIV LTR $\triangle$ TAR reporters in the presence of GAL4 and Sp1 sites. To determine the cis-acting sequences that may be required for GAL4-Tat activation of the HIV LTR, each HIV LTR deletion mutant described in Fig. 1A was modified as follows: The TAR element was destroyed by deleting TAR sequences downstream of position +25 , and six GAL4 sites were inserted upstream of the deletion end point as depicted schematically below the autoradiograph. The GAL4-Tat expression plasmid was constructed by inserting cTat into the GAL4 fusion expression plasmid PECE GAL4(1-147) (Sadowski and Ptashne 1989). Each G6 HIV LTR $\triangle T$ TAR deletion mutant was cotransfected with either CMV vector, GAL4-Tat, or cTat expression plasmids and $\mathrm{CH} 110$ reference plasmid into HeLa cells using the calcium phosphate coprecipitation technique. From $48-72 \mathrm{hr}$ after transfection, the cells were harvested and CAT activity was determined. $(C)$ GAL4-Tat contains a weak transcription activating region. Consensus Sp1 or USF DNA-binding sites were cloned in tandem upstream of the TATA box of the G6 (-31) HIV LTR $\triangle$ TAR reporter as shown below the autoradiograph. These reporters and G6 (-31) HIV LTR $\triangle T A R$ were then transfected into HeLa cells with either CMV, GAL4-Tat, or cTat expression plasmids and the CH110 reference plasmid. CAT activity was determined $48 \mathrm{hr}$ post-transfection. Upon a longer incubation of the CAT extract than that shown in lane 12 of Fig. 3B, GAL4-Tat is shown to activate transcription from the G6 (-31) HIV LTR $\triangle$ TAR reporter (see lanes 1,2$)$. (D) GAL4-Tat and GAL4-VP16 augments transcription to comparable levels. The G6 (-83) HIV LTR $\triangle T A R$ reporter was cotransfected in the presence or absence of GAL4-Tat or GAL4-VP16 into HeLa cells using the calcium phosphate coprecipitation technique. After $48 \mathrm{hr}$, the cells were harvested and CAT activity was determined.
} 
A

\begin{tabular}{|l|c|c|c|}
\hline ACTIVATOR & CMV & . TAT & $\begin{array}{c}\text { GAL4 } \\
\text {-TAT }\end{array}$ \\
\hline & & & \\
& & & \\
& & & \\
& & & \\
& & & \\
\hline 1 & 2 & 3 \\
\hline
\end{tabular}

HIV LTR CAT

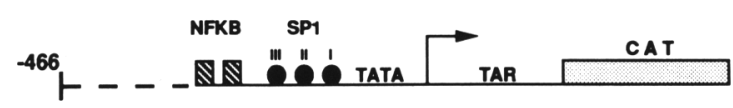

B

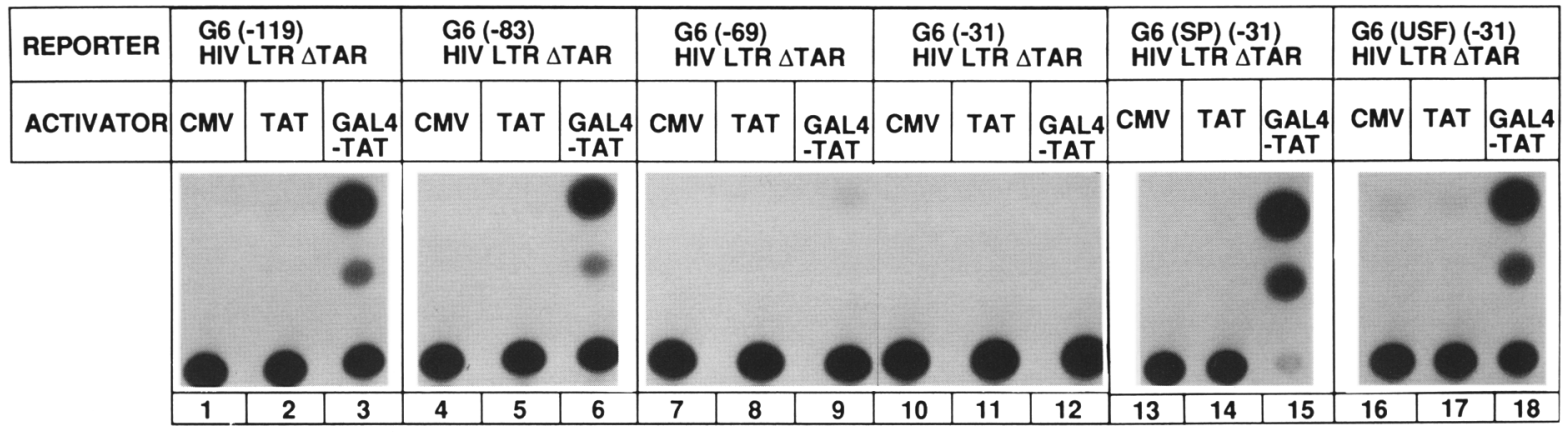

G6 (-119) HIV LTR $\triangle$ TAR

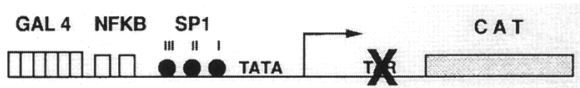

G6 (-83) HIV LTR $\triangle$ TAR

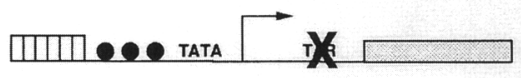

G6 (-69) HIV LTR $\triangle T A R$

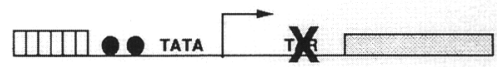

G6 (-31) HIV LTR $\triangle T A R$

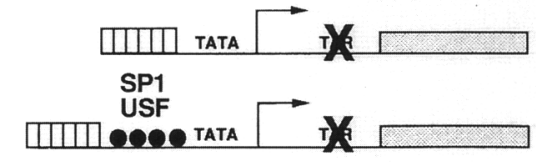
G6 (USF)

USF

C

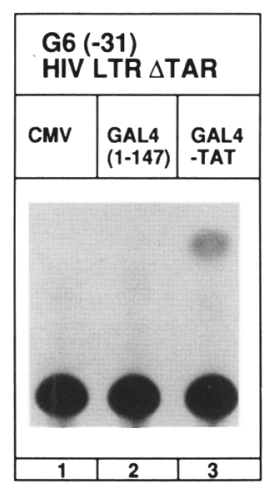

D
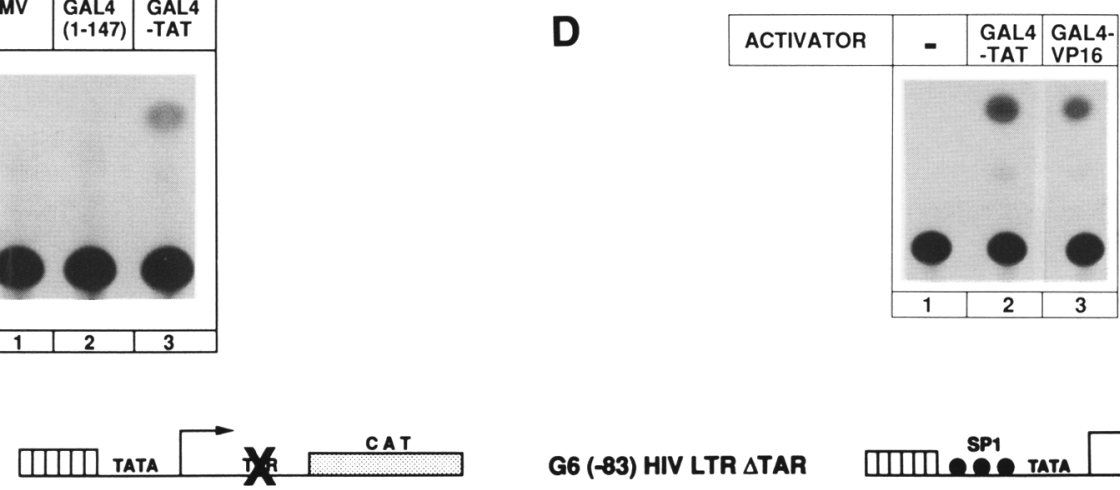

G6 (-83) HIV LTR $\triangle T$ TAR

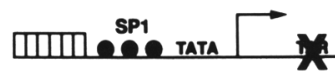

CAT

Figure 3. (See facing page for legend.) 
Figure 4. Mutational analysis of GAL4Tat function. (A) Schematic diagram of mutations. Mutations /Cys-22, His-33, Phe-38 and Lys-41), which disrupt Tat activation of the HIV LTR, were introduced into GAL4-Tat as shown. GAL4-Tat $\Delta N$ has the amino-terminal 21 amino acids of cTat deleted. GAL4-Tat $\Delta C$ has sequences downstream of amino acid 48 deleted, including the RNA-binding basic region of Tat. (B) Functional analysis. Each GAL4Tat derivative, together with the HIV LTR or G6 $(-83)$ HIV LTR $\triangle$ TAR reporter, was cotransfected into HeLa cells using the calcium phosphate coprecipitation technique. After $48 \mathrm{hr}$, the cells were harvested and CAT activity was determined.

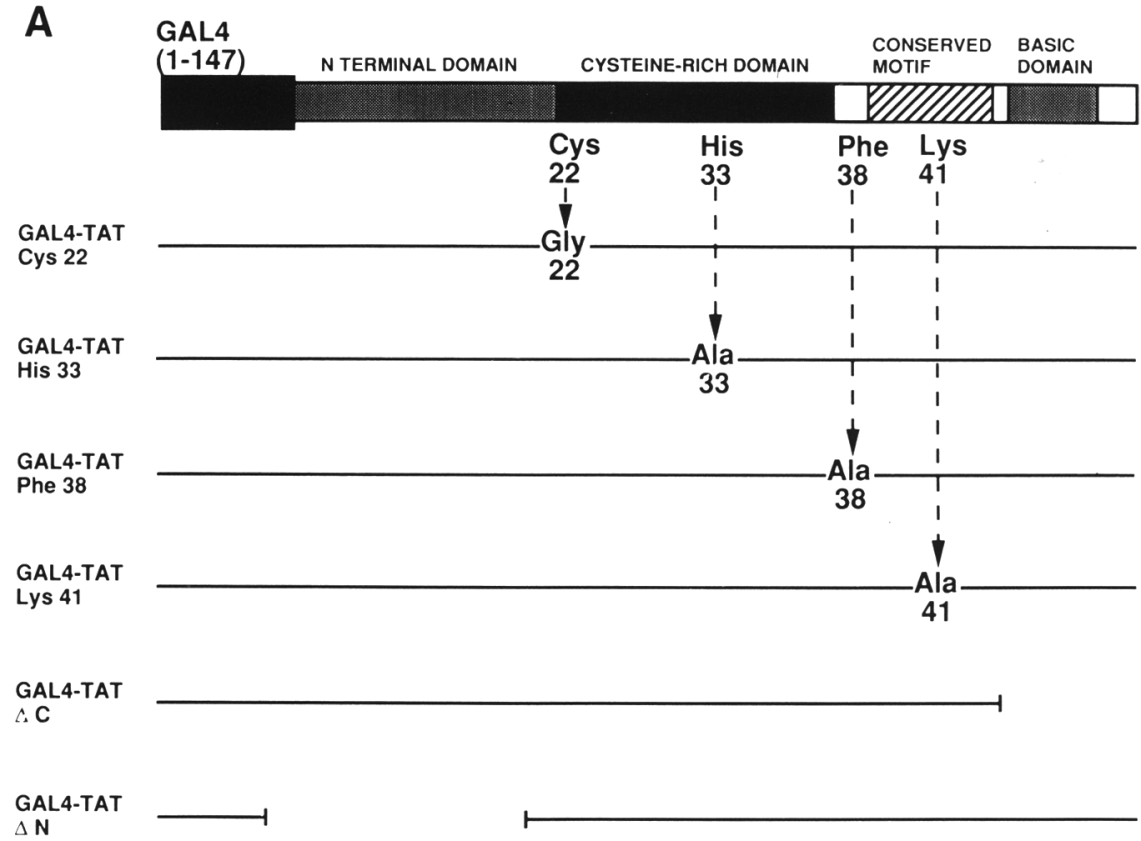

B

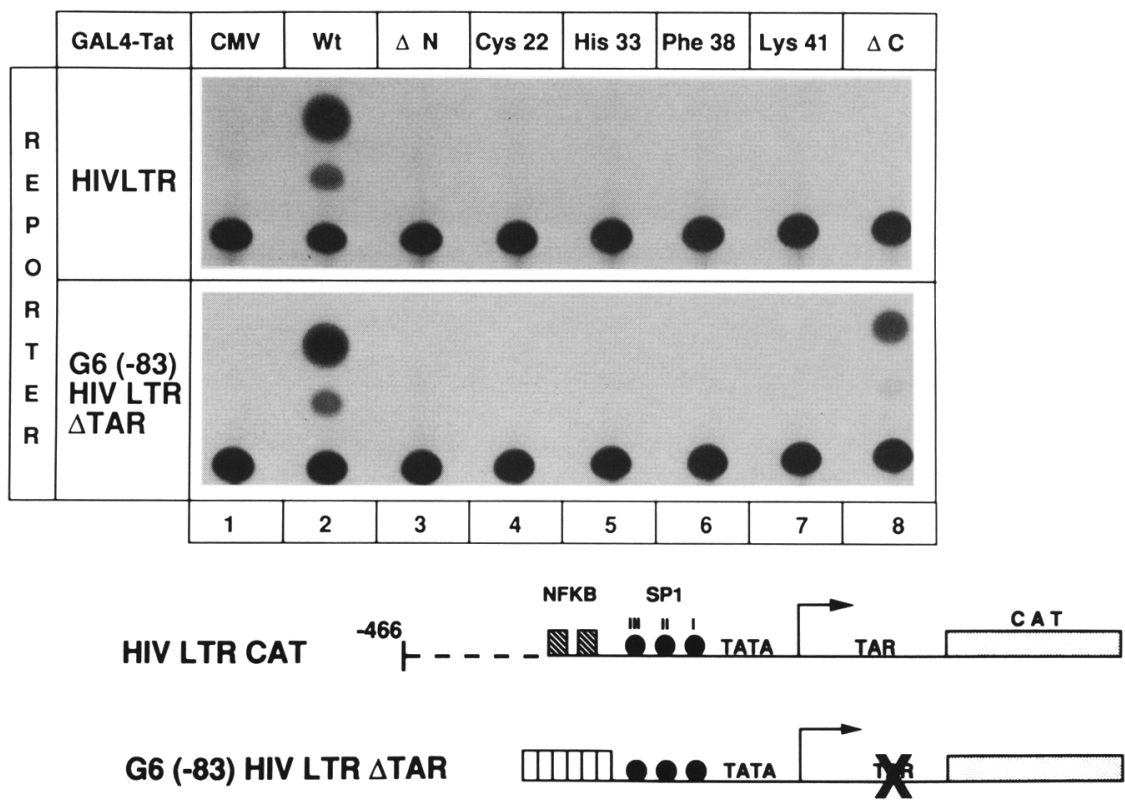

an in-frame deletion within the arginine-rich RNA-binding motif of Tat destroyed activation from the intact HIV LTR but not from the G6 (-83) HIV LTR $\triangle$ TAR (lane 8).

We conclude that the first 48 amino acids of Tat constitutes an activation domain that is required for function when Tat is tethered either to TAR RNA through the basic region of Tat or to upstream DNA through the GAL4 DNA-binding domain. The similar effect of the mutations when Tat is bound to RNA or DNA supports the relevance of the activation reported here. Our results also reveal that Tat has a modular structure containing at least two functional regions: an RNA-binding and a transcriptional activation domain.

\section{Discussion}

We have performed a series of protein fusion experiments that demonstrate similarities between the mechanism of action of the HIV-1 Tat protein and typical transcriptional activators. Our results indicate that both Tat and typical transcriptional activators (1) can function from upstream DNA-binding sites; (2) possess a 
modular structure, which includes a transcriptional activating region; (3) cooperate with promoter-bound cellular transcription factors to stimulate transcription; and (4) may act at similar steps in the transcription process. Below, we discuss the implication of these results to the mechanism of Tat action.

\section{Models for Tat action}

Two models have been proposed to explain how Tat activates transcription: One model argues that Tat acts on transcriptional initiation, whereas a second model suggests that Tat acts on transcriptional elongation (for reviews, see Sharp and Marciniak 1989; Cullen 1990).

The transcriptional initiation model (also called the RNA enhancer model; for review, see Sharp and Marciniak 1989) depicts Tat being recruited to the vicinity of the promoter by binding to nascent TAR RNA from where it would facilitate initiation of subsequent rounds of transcription. In support of this model are nuclear runon experiments, which show that Tat increases the density of RNA polymerase II from 9 - to 15 -fold within the first 25 nucleotides downstream of the transcriptional initiation site and thus proximal to TAR (Laspia et al. 1989,1990 ). Consistent with this model is the observation that Tat activation is efficient only when TAR is in close proximity to the promoter (Selby et al. 1989).

The RNA processivity model posits Tat augmenting transcriptional elongation by suppressing random termination of RNA polymerase II. In vitro transcription assays (Marciniak et al. 1990b) and in vivo nuclear run-on experiments (Kao et al. 1987; Laspia et al. 1989, 1990; Feinberg et al. 1991) indicate that Tat can increase RNA polymerase II processivity.

We point out two limitations of the evidence used to suggest that Tat increases transcriptional elongation but not initiation. First, in the in vitro transcription experiments (Marciniak et al. 1990b) it would have been difficult or impossible to observe an effect on initiation because the current cell-free systems do not support multiple rounds of transcription on a single template / see, e.g., Hai et al. 1988). Second, nuclear nun-on experiments demonstrate that activators other than Tat, such as the adenovirus Ela protein, also increased RNA polymerase II processivity (Laspia et al. 1989, 1990). The ability of an activator (or a combination of activators) to promote RNA polymerase II processivity was related directly to its ability to stimulate initiation (Laspia et al. 1989,1990 ). It is therefore conceivable that transcriptional initiation and elongation may be mechanistically linked. If this is the case, the relative ability of an activator to stimulate initiation versus elongation may depend on the particular conditions and assays used (see below).

Tat activates transcription from upstream DNA-binding sites

A major appeal of the RNA polymerase II processivity model has been the apparent analogy with bacteriophage antiterminators (Lazinski et al. 1989): Both Tat and bacteriophage antiterminators work through RNA-binding sites. Here, we demonstrate that Tat can stimulate transcription efficiently when bound to promoter DNA. According to current models (Roberts 1988), prokaryotic antiterminators would not function from upstream DNA-binding sites. Furthermore, the binding sites of bacteriophage antiterminators can function when moved far downstream from the transcription start site (Whalen and Das 1990), whereas TAR cannot.

\section{Tat has a modular structure that includes an activating region}

Typical transcriptional activators comprise two functional domains: a promoter-binding domain and a transcriptional activation region (Ptashne 1988). Our results and those from previous studies (Selby and Peterlin 1990) show that Tat also contains two separable functional domains: an arginine-rich RNA-binding domain that targets Tat to nascent TAR RNA and a transcriptional activating region. The arginine-rich RNA-binding domain of Tat is dispensable when Tat is tethered through the GAL4 DNA-binding domain. In contrast, the activating domain of Tat is essential when Tat is bound to either RNA or DNA. The correspondence between the effect of mutations when Tat is bound to RNA or to DNA is a strong argument for the relevance of the novel DNAbound activation reported here.

\section{Tat function requires cooperation with cellular transcription factors}

A prominent characteristic of eukaryotic transcriptional activators is their ability to cooperate with one another to stimulate transcription synergistically. Even for a very strong activator, such as GAL4-VP16, a single binding site is not sufficient for efficient transcriptional activation (Carey et al. 1990).

The experiments reported here demonstrate that Tat, bound either to downstream TAR RNA or to upstream GAL4 DNA-binding sites, requires cellular DNA-bound activators to stimulate transcription efficiently. Our results also show that Tat can cooperate with several unrelated transcriptional activating regions. However, optimal activation was obtained with $\mathrm{Sp} 1$, whose binding sites are present in the natural HIV LTR. By analogy, cellular activators also display differences in their abilities to cooperate with activators of other classes (Lin et al. 1988; Wang and Gralla 1991). We therefore imagine that the activating region of Tat, tethered to either RNA or to DNA, cooperates with the activation regions of promoter-bound cellular factors to stimulate transcription.

The finding that Tat function requires cooperativity with cellular transcription factors is reminiscent of studies with other viral activators. For example, bovine papilloma virus E2 acts with cellular Spl (Li et al. 1991), adenovirus E1a acts with cellular ATF-2 (Liu and Green 1990) and Oct-4 (Schöler et al. 1991), and herpesvirus 
VP16 acts with cellular Oct-1 /Gerster and Roeder 1988; Stern et al. 1989).

\section{Which step in transcription does Tat affect?}

Although our experiments do not directly address the step in the transcription process affected by Tat, the combined results allow us to speculate on this question. It is generally believed that typical cellular activators enhance transcriptional initiation (Lewin 1990). Recent in vitro experiments have provided direct support for this idea: An acidic activator increases transcriptional initiation by facilitating preinitiation complex assembly (Lin and Green 1991). If Tat acts at a postinitiation step, we would predict that the fold induction by Tat should be independent of the level of transcription in its absence, that is, activation by DNA-bound cellular activators and Tat should be multiplicative. On the contrary, we find that as transcription increases, the effect of Tat is diminished. The simplest interpretation of these results is that Tat acts on the same step as the DNA-bound cellular activators. Consistent with this notion, Tat and the strong acidic activator GAL4-VP16 stimulate transcription to approximately the same maximal level when Tat is bound either to RNA (Fig. 2B) or to DNA (Fig. 3D). Our results do not rule out the possibility that DNA-bound activators and Tat affect both initiation and RNA polymerase II processivity.

These data may be relevant to the interpretation of a recent study by Feinberg et al. (1991). These investigators found that in a T-lymphoblastoid cell line containing a Tat-defective provirus, addition of Tat stimulated transcriptional elongation but not initiation. The CEM T-lymphoblastoid cell line used in this study was generated by infection with a $\mathrm{Tat}^{-} \mathrm{Nef}^{-} \mathrm{HIV}$ provirus. Recent evidence (for review, see Nabel 1991) suggests that HIV infection activates NF- $\mathrm{kB}$, which binds to the HIV-1 LTR (Nabel and Baltimore 1987). Thus, NF- $\mathrm{kB}$ or other transcription factors may have been activated in these cells, driving transcriptional initiation of the provirus to a maximum level. This would explain why Tat affected elongation but not initiation.

\section{Role of cellular TAR-binding proteins}

Previous studies have described cellular proteins that bind to TAR RNA, some of which interact specifically with the loop (Gatignol et al. 1989,1991; Gaynor et al. 1989; Marciniak et al. 1990a). Mutation of these TAR loop sequences diminishes Tat responsiveness (Feng and Holland 1988; Berkout and Jeang 1989; Dingwall et al. 1990; Roy et al. 1990b/ but does not affect binding of Tat to TAR (Dingwall et al. 1989, 1990; Weeks et al. 1990). What, then, is the function of the cellular TAR-binding proteins?

A conclusion of the results presented here, as well as those from previous protein fusion experiments /Selby and Peterlin 1990; Southgate et al. 1990), is that the TAR element is dispensable for Tat responsiveness. Thus, the cellular TAR-binding proteins are not required for Tat responsiveness when Tat is directed to the promoter by another means. On the basis of these results, we suggest that the role of these cellular TAR-binding proteins may be to facilitate or stabilize the Tat-TAR interaction in vivo.

\section{Why is Tat an RNA-bound activator?}

Why did HIV evolve a system in which the transcriptional activator functions through an RNA-binding site? A unique feature of the mechanism of action of Tat is that the number of Tat-binding sites increases as transcriptional initiation increases. We imagine that once transcription is triggered, Tat is recruited to the promoter by binding to nascent TAR RNA and cooperates with upstream transcription factors to stimulate transcription and thereby increase the number of Tat-binding sites. A maximal level of transcription would be achieved rapidly and, conversely, would also decrease rapidly. Such rapid responsiveness may be an important component of the mechanism by which HIV enters latency or, conversely, is activated from the latent state.

\section{Materials and methods}

Plasmid constructs

Specific HIV LTR deletions were constructed by cleaving the wild-type HIV-1 LTR with either EcoRV $(-119)$, BstNI $(-83)$, HaelII $(-69)$, or Mnll $(-31)$, and then HindIII $(+84)$ downstream of the TAR element. These fragments were then cloned between the $\mathrm{XbaI}$ and $\mathrm{BamHI}$ sites of the G1 Elb CAT reporter (described in Lillie and Green 1989). The "add-back" reporters were constructed by cloning 2-5 oligonucleotides containing consensus ATF or USF (Lin et al. 1988) or Spl (5'-TCGATGGGCGGGACG-3'| binding sites into the Sall site of the 1-31) HIV LTR reporter immediately upstream of the HIV-1 LTR TATA box. The G5 $(-31)$ HIV LTR reporter was constructed by inserting the Mnll $(-31)-$ HindIII $(+84)$ fragment of the HIV-1 LTR between the Xbal and BamHI sites of the G5 E1b CAT reporter (Lillie and Green 1989). The G6 HIV LTR reporters were constructed by cloning the HindIII in the pSP72 polylinker upstream of the insert $\mid$ to BgIII $(+25)$ fragment of the HIV LTR deletion or add-back reporters between the $X b a I$ and BamHI sites of the G5 Elb CAT reporter.

The GAL4-Spl derivative was constructed by cleaving pBSSpl-fl plasmid, containing the full-length Spl cDNA, with AvaI and HindII. The resulting fragment, corresponding to the activation region A of Spl (Courey and Tiian 1988), was subsequently cloned into the BamHI site of PECE GAL4|1-147)|Sadowski and Ptashne 1989). GAL4-VPl6 (Sadowski et al. 1988), GAL4-Ela (Lillie and Green 1989), and cTat expression plasmids (Cullen 1986) have been described previously. The GAL4 Tat derivative was constructed by inserting HIV-1 sequences encoding Tat (amino acids $1-83$ ) into the EcoRI site of PECE GAL4(1-147) (Sadowski and Ptashne 1989). In a similar manner, the previously described Tat mutants Cys-22, His-33, Phe-38, and Lys-41 (Rice and Carlotti 1990) and deletion mutants $\Delta C$ and $\Delta \mathrm{N}$ were cloned into the EcoRI site of PECE GAL4(1-147) and sequenced.

\section{Transfections}

The calcium phosphate coprecipitation transfection protocol is the same as that described in Weber et al. (1984), except that the 
dimethylsulfoxide (DMSO) shock was omitted. Typically, a to tal of 20-25 $\mu \mathrm{g}$ of DNA/10-cm-diam. dish was used in each experiment $-5 \mu \mathrm{g}$ reporter plasmid, and $10 \mu \mathrm{g}$ activator expression plasmid. pSP72 plasmid was used as carrier DNA. The calcium phosphate precipitate remained on the cells for 18-24 hr. The cells were then washed three to five times, refed with media, and incubated for an additional $48 \mathrm{hr}$. CAT extracts were then prepared as described previously (Lillie and Green 1989).

HeLa cells were transfected by DEAE-dextran as described previously (Dorsett et al. 1983). Briefly, cells were washed, trypsinized, and incubated with $3 \mu \mathrm{g}$ of DNA total in $1 \mathrm{ml}$ of DEAE-dextran $(240 \mu \mathrm{g} / \mathrm{ml}$; Pharmacia $)$ in $1 \times$ PBS for $15 \mathrm{~min}$ at room temperature. The cells were then washed twice, refed with media, and incubated for an additional $48 \mathrm{hr}$ before harvest and preparation of CAT extracts. No DMSO or glycerol shocks or chloroquine treatment proved necessary. The reproducibility of the transfection experiments was ascertained by repeating each experiment from two to five times. Comparable results were obtained in all instances. The experiments of Figure 1, A and $B$, were also repeated in Jurkat $T$ cells with similar results (data not shown).

\section{Acknowledgments}

We thank Al Courey for providing the Spl cDNA clone and Andrew Rice for the Tat point mutants. C.S. is a Scholar of the American Foundation for AIDS Research. This work was supported by a National Institutes of Health grant awarded to M.R.G.

The publication costs of this article were defrayed in part by payment of page charges. This article must therefore be hereby marked "advertisement" in accordance with 18 USC section 1734 solely to indicate this fact.

\section{References}

Berkhout, B. and K.-T. Jeang. 1989. Trans-activation of human immunodeficiency virus type 1 is sequence-specific for both the single stranded bulge and loop of the trans-acting-responsive hairpin: A quantitative analysis. J. Virol. 63: 5501-5504.

Berkhout, B., A. Gatignol, A.B. Rabson, and K.-T. Jeang. 1990. TAR-independent activation of the HIV-1 LTR: Evidence that Tat requires specific regions of the promoter. Cell 62: 757-767.

Calnan, B.J., S. Biancalana, D. Hudson, and A.D. Frankel. 1991a. Analysis of arginine-rich peptides from the HIV-1 Tat protein reveals unusual features of RNA-protein recognition. Genes \& Dev. 5: 201-210.

Calnan, B.J., B. Tidor, S. Biancalana, D. Hudson, and A.D. Frankel. 1991b. Arginine-mediated RNA recognition: The arginine fork. Science 252: 1167-1170.

Carey, M., Y.-S. Lin, M.R. Green, and M. Ptashne. 1990. A mechanism for synergistic activation of a mammalian gene by GAL4 derivatives. Nature 345: 361-364.

Cordingley, M.G., R.L. LaFemina, P. L. Callahan, J.H. Condra, V.V. Sardana, D.J. Graham, T.M. Nguyen, K. LeCrow, L. Gotlib, A.J. Schlabach, and R.J. Colonno. 1990. Sequencespecific interaction of Tat protein and Tat peptides with the transactivation-responsive sequence element of human immunodeficiency virus type 1 in vitro. Proc. Natl. Acad. Sci. 87: 8985-8989.

Courey, A.J. and R. Tjian. 1988. Analysis of Spl in vivo reveals multiple transcriptional domains, including a novel glutamine-rich activation motif. Cell 55: 887-898.

Cullen, B.R.1986. Trans-activation of human immunodeficien- cy virus occurs via a bimodal mechanism. Cell 46: 973-982.

1990. The HIV-1 Tat protein : An RNA sequence specific processivity factor? Cell 63: 655-657.

Dingwall, C., I. Ernberg, M.J. Gait, S.M. Green, S. Heaphy, J. Karn, A.D. Lowe, M. Singh, M.A. Skinner, and R. Valerio. 1989. Human immunodeficiency virus-1 tat protein binds the trans-activation-responsive region (TAR) RNA in vitro. Proc. Natl. Acad. Sci. 86: 6925-6929.

Dingwall, C., I. Emberg, M.J. Gait, S.M. Green, S. Heaphy, J. Karn, A.D. Lowe, M. Singh, and M.A. Skinner. 1990. HIV-1 tat protein stimulates transcription by binding to a U-rich bulge in the stem of the TAR RNA structure. EMBO $/$. 9: 4145-4153.

Dorsett, D., I. Keshet, and E. Winocour. 1983. Quantitation of a simian virus 40 non-homologous recombination pathway. $J$. Virol. 48: 218-228.

Feinberg, M.B., D. Baltimore, and A.D. Frankel. 1991. The role of Tat in the immunodeficiency virus life cycle indicates a primary effect on transcriptional elongation. Proc. Natl. Acad. Sci. 88: 4045-4049.

Feng, S. and E.C. Holland. 1988.. HIV-1 tat trans-activation requires the loop sequence within tar. Nature 334: 165-167.

Garcia, J.A., L. Harrich, R. Pearson, R. Mitsuyasu, and R.B. Gaynor. 1988. Functional domains required for tat-induced transcriptional activation of the HIV-1 long terminal repeat. EMBO I. 7: 3143-3147.

Gatignol, A., A. Kumar, A. Rabson, and K.-T. Jeang. 1989. Identification of cellular proteins that bind to the human immunodeficiency virus type 1 trans-activation-responsive TAR element RNA. Proc. Natl. Acad. Sci. 86: 7828-7832.

Gatignol, A., A. Buckler-White, B. Berkout, and K.-T. Jeang. 1991. Characterization of a human TAR-RNA binding protein that activates the HIV-1 LTR. Science 251: 1597-1600.

Gaynor, R., E. Soultanakis, M. Kuwabara, J. Garcia, and D.S. Sigman. 1989. Specific binding of a HeLa cell nuclear protein to RNA sequences in the human immunodeficiency virus transactivating region. Proc. Natl. Acad. Sci. 86: 4858-4862.

Gerster, T. and R.G. Roeder. 1988. A herpesvirus trans-activating protein interacts with transcription factor OTF-1 and other cellular proteins. Proc. Natl. Acad. Sci. 85: 6347-6351.

Hai, T., M. Horikoshi, R.G. Roeder, and M.R. Green. $1988 .$. Analysis of the role of the transcription factor ATF in the assembly of a functional preinitiation complex. Cell 54: 1043-1051.

Harrich, D., J. Garcia, F. Wu, R. Mitsuyasu, J. Gonzalez, and R. Gaynor. 1989. Role of Spl-binding domains in in vivo transcriptional regulation of the human immunodeficiency virus type 1 long terminal repeat. J. Virol. 63: 2585-2591.

Hauber, J. and B.R. Cullen. 1988. Mutational analysis of the trans-activation-responsive region of the human immunodeficiency virus type 1 long terminal repeat. J. Virol. 62: 673679.

Jakobovits, A., D.H. Smith, E.B. Jakobovits, and D.J. Capon. 1988. A discrete element $3^{\prime}$ of human immunodeficiency virus 1 (HIV-1) and HIV-2 mRNA initiation sites mediates transcriptional activation by an HIV trans activator. Mol. Cell. Biol. 8: 2555-2561.

Jones, K.A., J.T. Kadonaga, P.A. Luciw, and R. Tjian. 1986. Activation of the AIDS retrovirus promoter by the cellular transcription factor, Spl. Science 232: 755-759.

Kao, S.Y., A.F. Calman, P.A. Luciw, and B.M. Peterlin. 1987. Anti-termination of transcription within the long terminal repeat of HIV-1 by tat gene product. Nature 330: $489-493$.

Kuppuswamy, M., T. Subramanian, A. Srinivasan, and G. Chinnadurai. 1989. Multiple functional domains of Tat, the trans-activator of HIV-1, defined by mutational analysis. $\mathrm{Nu}$ - 
cleic Acids Res. 17: 3551-3561.

Laspia, M.F., A.P. Rice, and M.B. Mathews. 1989. HIV-1 Tat protein increases transcriptional initiation and stabilizes elongation. Cell 59: 283-292.

- 1990. Synergy between HIV-1 Tat and adenovinus Ela is principally due to stabilization of transcriptional elongation. Genes \& Dev. 4: 2397-2408.

Lazinski, D., E. Grzadzielska, and A. Das. 1989. Sequence-specific recognition of RNA hairpins by bacteriophage anti-terminators requires a conserved arginine-rich motif. Cell 59: 207-218.

Leonard, J., C. Parrot, J. Buckler-White, W. Turner, E.K. Ross, M.A. Martin, and A.B. Rabson. 1989. The NF-kB-binding sites in the human immunodeficiency virus type 1 long terminal repeat are not required for virus infectivity. $/$. Virol. 63: 4919-4924.

Lewin, B. 1990. Commitment and activation at pol II promoters: A tail of protein-protein interaction. Cell 61: 11611164.

Li, R., J.D. Knight, S.P. Jackson, R. Tjian, and M.R. Botchan. 1991. Direct interaction between Spl and the BPV enhancer E2 protein mediates synergistic activation of transcription. Cell 65: 493-505.

Lillie, J.W. and M.R. Green. 1989. Transcription activation by the adenovirus Ela protein. Nature 338: 39-44.

Lin, Y.-S. and M.R. Green. 1991. Mechanism of action of an acidic transcriptional activator. Cell 64: 971-981.

Lin, Y.-S., M. Carey, M. Ptashne, and M.R. Green. 1988. GAL4 derivatives function alone and synergistically with mammalian activators in vitro. Cell 54: 659-664.

Liu, F. and M.R. Green. 1990. A specific member of the ATF transcription factor family can mediate transcription activation by the adenovirus Ela protein. Cell 61: 1217-1224.

Marciniak, R.A., M.A. Garcia-Blanco, and P.A. Sharp. 1990a. Identification and characterization of a HeLa nuclear protein that specifically binds to the trans-activation-response (TAR) element of human immunodeficiency virus. Proc. Natl. Acad. Sci. 87: 3624-3628.

Marciniak, R.A., B.J. Cainan, A.D. Frankel, and P.A. Sharp. 1990b. HIV-1 Tat protein trans-activates transcription in vitro. Cell 63: 791-802.

Martin, K.J., J.W. Lillie, and M.R. Green. 1990. Evidence for interaction of different eukaryotic transcriptional activators with distinct cellular targets. Nature 346: 147-152.

Mermod, N., E.A. O'Neill, T.J. Kelly, and R. Tiian. 1989. The proline-rich transcriptional activator of CTF/NF-l is distinct from the replication and DNA binding domain. Cell 58: 741-753.

Mitchell, P.J. and R. Tiian. 1989. Transcriptional regulation in mammalian cells by sequence-specific DNA binding proteins. Science 245: 371-378.

Muesing, M.A., D.H. Smith, and D.J. Capon. 1987. Regulation of mRNA accumulation by a human immunodeficiency virus trans-activator protein. Cell 48: 691-701.

Nabel, G. 1991. Tampering with transcription. Nature 350: 658.

Nabel, G. and D. Baltimore. 1987. An inducible transcription factor activates expression of human immunodeficiency virus in T cells. Nature 326: 711-713.

Peterlin, B.M., P.A. Luciw, P.J. Barr, and M.D. Walker. 1986. Elevated levels of mRNA can account for the trans-activation of human immunodeficiency virus (HIV). Proc. Natl. Acad. Sci. 83: 9734-9738.

Ptashne, M. 1988. How transcriptional activators work. Nature 335: 683-689.

Ptashne, M. and A.A.F. Gann. 1990. Activators and targets. Nature 346: 329-331.
Rappaport, J., S.-J. Lee, K. Khalili, and F. Wong-Staal. 1989. The acidic amino-terminal region of the HIV-1 Tat protein constitutes an essential activating domain. New Biol. 1: 101110.

Rice, A.P. and M.B. Mathews. 1988. Transcriptional but not translational regulation of HIV-1 by the tat gene product. Nature 332: 551-553.

Rice, A.P. and F. Carlotti. 1990. Mutational analysis of the conserved cysteine-rich region of the human immunodeficiency virus type 1 Tat protein. I. Virol. 64: 1864-1868.

Roberts, J.W. 1988. Phage lambda and the regulation of transcription termination. Cell 52: 5-6.

Rosen, C.A. and G.N. Pavlakis. 1990. Tat and Rev: Positive regulators of HIV gene expression. AIDS 4: 499-509.

Rosen, C.A., J.G. Sodroski, and W.A. Haseltine. 1985. The location of cis-acting regulatory sequences in the human $\mathrm{T}$ cell lymphotropic vinus type III (HTLV-III/LAV) long terminal repeat. Cell 41: 813-823.

Roy, S., U. Delling, C.-H. Chen, C.A. Rosen, and N. Sonenberg. 1990a. A bulge structure in HIV-1 TAR is required for Tat binding and Tat-mediated trans-activation. Genes \& Dev. 4: 1365-1373.

Roy, S., N.T. Parkin, C. Rosen, J. Itovich, and N. Sonenberg. $1990 \mathrm{~b}$. Structural requirements for trans-activation of human immunodeficiency virus type 1 long terminal repeatdirected gene expression by tat: Importance of base-pairing, loop sequence and bulges in the tat-responsive sequence. $I$. Virol. 64: 1402-1406.

Ruben, S., A. Perkins, R. Purcell, K. Joung, R. Sia, R. Burghoff, W.A. Haseltine, and C.A. Rosen. 1989. Structural and functional characterization of human immunodeficiency virus tat protein. I. Virol. 63: 1-8.

Sadowski, I. and M. Ptashne. 1989. A vector for expressing GAL4(1-147) fusions in mammalian cells. Nucleic Acids Res. 17: 7539.

Sadowski, I., J. Ma, S. Triezenberg, and M. Ptashne. 1988. GAL4VP16 is an unusually potent transcriptional activator. $\mathrm{Na}$ ture 335: 563-564.

Schöler, H. R., T. Ciesiolka, and P. Gruss. 1991. A nexus between Oct-4 and Ela: Implications for gene regulation in embryonic stem cells. Cell 66: 291-304.

Selby, M.J. and B.M. Peterlin. 1990. Trans-activation by HIV-1 Tat via a heterologous RNA binding protein. Cell 62: 769776.

Selby, M.J., E.S. Bain, P.A. Luciw, and B.M. Peterlin. 1989. Structure, sequence, and position of the stem-loop structure in tar determine transcriptional elongation by tat through the HIV-1 long terminal repeat. Genes \& Dev. 3: 547-558.

Sharp, P. 1991. TFIIB or not TFIIB? Nature 351: 16-18.

Sharp, P.A. and R.A. Marciniak. 1989. HIV TAR: An RNA enhancer? Cell 59: 229-230.

Southgate, C., M.L. Zapp, and M.R. Green. 1990. Activation of transcription by HIV-1 Tat protein tethered to nascent RNA through another protein. Nature 345: 640-642.

Stern, S., M. Tanaka, and W. Herr. 1989. The Oct-1 homeodomain directs formation of a multiprotein-DNA complex with the HSV trans-activator VP16. Nature 341: 624-630.

Tiley, L.S., P.H. Brown, and B.R. Cullen. 1990. Does the human immunodeficiency virus Tat trans-activator contain a discrete activation domain? Virology 178: 560-567.

Triezenberg, S.J., R.C. Kingsbury, and S.L. McKnight. 1988. Functional dissection of VP16, the trans-activator of herpes simplex virus immediate early gene expression. Genes \& Dev. 2: 718-729.

Vaishnav, Y.N. and F. Wong-Staal. 1991. The biochemistry of AIDS. Annu. Rev. Biochem. 60: 577-630. 
Wang, W. and J.D. Gralla. 1991. Differential ability of proximal and remote element pairs to cooperate in activating RNA polymerase II transcription. Mol. Cell. Biol. 11: 4561-4571.

Weber, F., J. de Villiers, and W. Schaffner. 1984. An SV40 "enhancer trap" incorporates exogenous enhancers or generates enhancers from its own sequences. Cell 36: 983-992.

Weeks, K.M. and D.M. Crothers. 1991. RNA recognition by Tat-derived peptides : Interaction in the major groove? Cell 66: $577-588$.

Weeks, K.M., C. Ampe, S.C. Schultz, T.A. Steitz, and D.M Crothers. 1990. Fragments of the HIV-1 Tat protein specifically bind TAR RNA. Science 249: 1281-1285.

Whalen, W.A. and A. Das. 1990. Action of an RNA site at a distance: Role of the nut genetic signal in transcription antitermination by phage $\lambda \mathrm{N}$ gene product. New Biol. 2: $975-$ 991.

Zimmermann, K., M. Dobrovnik, C. Ballaun, D. Bevec, I. Hauber, and E. Böhnlein. 1991. Trans-activation of the HIV-1 LTR by the HIV-1 Tat and HTLV-1 Tax proteins is mediated by different cis-acting sequences. Virology 182: 874-878. 


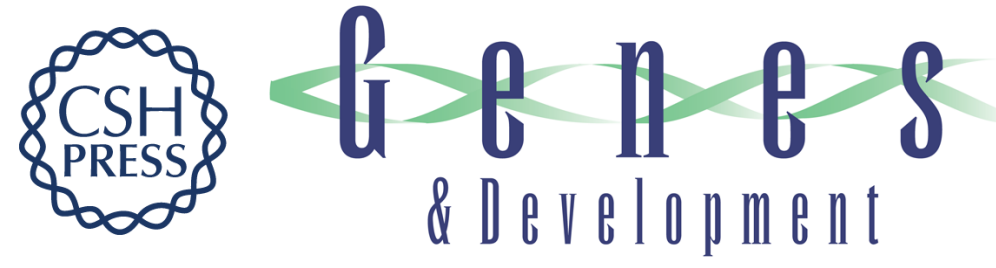

\section{The HIV-1 Tat protein activates transcription from an upstream DNA-binding site: implications for Tat function.}

C D Southgate and M R Green

Genes Dev. 1991, 5:

Access the most recent version at doi:10.1101/gad.5.12b.2496

References This article cites 74 articles, 28 of which can be accessed free at:

http://genesdev.cshlp.org/content/5/12b/2496.full.html\#ref-list-1

License

Email Alerting

Service

Receive free email alerts when new articles cite this article - sign up in the box at the top right corner of the article or click here.

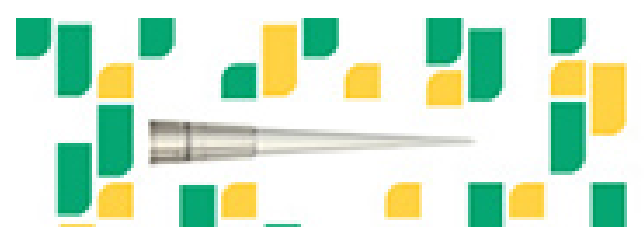

Focused on your science. 